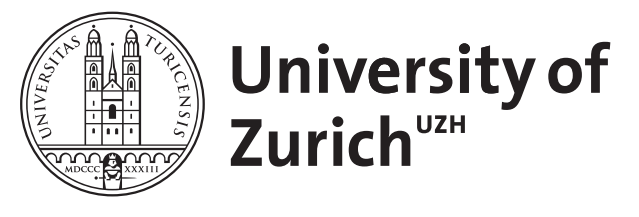

\title{
Kinetics of crimp and slope grip in rock climbing
}

\author{
Schweizer, A ; Hudek, R
}

\begin{abstract}
The aim was to investigate differences of the kinetics of the crimp and the slope grip used in rock climbing. Nine cadaver fingers were prepared and fixated with the proximal phalanx in a frame. The superficial (FDS) and deep (FDP) flexor tendons were loaded selectively and together with $40 \mathrm{~N}$ in the crimp grip (PIP joint flexed $90^{\circ} / \mathrm{DIP}$ joint hyperextended) and the slope grip position $\left(<25^{\circ}\right.$ flexed $/ 50^{\circ}$ flexed respectively). Five different grip sizes were tested and the flexion force which was generated to the grip was measured. In the crimp grip the FDP generated more flexion force in small sized holds whereas the FDS generated more force in the larger holds. During the slope grip the FDP was more effective than the FDS. While both tendons were loaded, the flexion force was always greater during crimp grip compared with the slope grip. The FDP seems to be most important for very small holds using the crimp grip but also during slope grip holds whereas the FDS is more important for larger flat holds.
\end{abstract}

DOI: https://doi.org/10.1123/jab.27.2.116

Posted at the Zurich Open Repository and Archive, University of Zurich

ZORA URL: https://doi.org/10.5167/uzh-54208

Journal Article

Accepted Version

Originally published at:

Schweizer, A; Hudek, R (2011). Kinetics of crimp and slope grip in rock climbing. Journal of Applied Biomechanics, 27(2):116-121.

DOI: https://doi.org/10.1123/jab.27.2.116 
Publisher: KINETICS; Journal: JAB:Journal of Applied Biomechanics; Copyright:

Volume: ; Issue: ; Manuscript: 20100048; Month: ; Year:

DOI: ; TOC Head: ; Section Head: ; Article Type: Article

Andreas Schweizer and Robert Hudek are with Universitätsklinik Balgrist, Orthopädie, Zürich, Switzerland. Schweizer and Hudek

Kinetics of Crimp and Slope Grip

\title{
Kinetics of Crimp and Slope Grip in Rock Climbing
}

\author{
Andreas Schweizer and Robert Hudek
}

\begin{abstract}
The aim was to investigate differences of the kinetics of the crimp and the slope grip used in rock climbing. Nine cadaver fingers were prepared and fixated with the proximal phalanx in a frame. The superficial (FDS) and deep (FDP) flexor tendons were loaded selectively and together with $40 \mathrm{~N}$ in the crimp grip (PIP joint flexed 90\%/DIP joint hyperextended) and the slope grip position $\left(<25^{\circ}\right.$ flexed $/ 50^{\circ}$ flexed respectively). Five different grip sizes were tested and the flexion force which was generated to the grip was measured. In the crimp grip the FDP generated more flexion force in small sized holds whereas the FDS generated more force in the larger holds. During the slope grip the FDP was more effective than the FDS. While both tendons were loaded, the flexion force was always greater during crimp grip compared with the slope grip. The FDP seems to be most important for very small holds using the crimp grip but also during slope grip holds whereas the FDS is more important for larger flat holds.
\end{abstract}

Keywords: sport climbing, rock climbing, crimp grip, grip force, kinetics

Sport climbing has become very popular in the last 25 years. Safe environments and improvement in protective equipment allowed climbers to focus on difficult climbing movements leading to a rise in the maximum grade of difficulty on steep, overhanging routes. The holds are often very small allowing contact to the fingers only with their distal phalanges. Such small ledge-like holds are often grasped with the so called crimp grip position (Schweizer, 2001) where the proximal interphalangeal (PIP) joint is flexed $90^{\circ}$ or more and the distal interphalangeal (DIP) joint is hyperextended (Figure 1). In contrast small holes for one or two fingers are usually grasped with the slope grip position where the DIP joint is flexed maximally, the PIP nearly extended. The advantage of holding one or two finger pockets in this manner is that the completely flexed neighbor fingers may increase holding strength (Schweizer, 2001) by a force transfer in the common origin of the flexor profundus muscle in the proximal forearm according to the syndrome of the quadriga (Verdan, 1960). However the reason for the preference of the crimp grip position is still under discussion. Advantageous is the fact that the thumb comes into contact with the hold (Figure 1) and is adding to the holding strength (Schweizer, 2001). Another reason may be that friction between the flexor tendons and the pulleys of the tendon sheath is greater with a more flexed PIP joint (Moor, 2009; Schweizer, 2003), which would increase the holding strength in static or near eccentric situations. Indirect in vivo methods (Vigouroux, 2006) tried to estimate the activation, moments and force transmission of the FDS and the FDP tendon for the different grip position. They showed that the FDP was the main flexor during crimp grip and that the FDS has an unexpectedly high activity during the slope grip position. It is unknown whether this high activity of the FDS, even higher than the FDP, is mechanically effective in generating flexion force in the slope grip position although. Direct measurements of tendon forces and the resulting finger flexion strength are hardly feasible in vivo and have not been performed yet. But also in vivo measurements could not exclude any muscular cocontraction influencing the tendon force FDS and FDP ratio. The aim of this study was to quantify the finger flexion forces in the DIP and PIP joint for two different climbing specific finger positions according to a known tendon tension to quantify the mechanical effectiveness of each tendon, the FDS and the FDP. To exclude the difficulties measuring muscle forces in vivo we performed the tests on human cadaver fingers where defined forces could be applied to the tendons. The results are aimed to better understand the biomechanics of the finger positions in climbers by adding information to Vigouroux's (2006) findings.

$\backslash$ Insert Figure 1\

\section{Methods}

\section{Specimens}

Nine long fingers were obtained from three fresh-frozen, non-embalmed, adult cadaver hands. The hands were 
Publisher: KINETICS; Journal: JAB:Journal of Applied Biomechanics; Copyright:

$$
\begin{aligned}
& \text { Volume: ; Issue: ; Manuscript: 20100048; Month: ; Year: } \\
& \text { DOI: ; TOC Head: ; Section Head: ; Article Type: Article }
\end{aligned}
$$

obtained within $24 \mathrm{hr}$ of accidental amputation and then stored frozen at $-20{ }^{\circ} \mathrm{C}$. Fourteen hours before testing they were thawed to room temperature. The entire finger including the metacarpophalangeal joint was separated from the hand and the skin left intact. The tendons were cut distal to the musculotendinous junction of the FDS and FDP muscle. Each tendon end was sutured with a braided polyester filament (Ethibond Excel 2, Johnson \& Johnson company) using a Krakow suture technique. Two $2.7 \mathrm{~mm}$ Schanz screws were inserted dorsally into the proximal phalanx after stitch cuts of the skin and extensor tendons to allow a rigid fixation of the specimen to the testing frame (described below) by means of an external fixation system. Lateral radiographs were performed from all fingers to define the center of rotation in the DIP and PIP joints (center of the corresponding condyles), to measure the length of the phalanges and to localize the positions of the force transducer to calculate the flexor tendon moment arms (Figure 2).

$\backslash$ Insert Figure $2 \backslash$

\section{Testing Frame Device}

A custom-made frame with components of the small fragment external fixation system (Synthes, Solothurn, Switzerland) was constructed where the finger could be fixated on the Schanz screws. The proximal phalanx was positioned in a vertical position so that the flexor tendons could be loaded with weights in a vertical direction. A Plexiglas plate of $2 \times 2 \times 0.8 \mathrm{~cm}$ size with a smooth, plane surface and rounded edges was used to simulate the climbing hold (Figure 3). The plate was mounted on the frame with a mobile arm to allow changing the position in all directions. A piezoelectric force transducer (Kistler 9301A SN488642, Winterthur, Switzerland) was intercalated between the plate and the frame to measure the vertical force generated by the finger. To exclude that the measurements of the transducer is influenced by an eccentric load to the Plexiglas plate during simulation of small holds, the plate and the sensor was tested with a defined punctual load at different positions of the plate. There was no difference between load at the center and the peripheral area of the plate greater than $1 \%$ detectable.

$\backslash$ Insert Figure $3 \backslash$

\section{Measurements}

The artificial plane hold was set in a position that the PIP joint was flexed $90^{\circ}$ and the DIP joint completely extended (crimp grip position). The artificial hold with the load cell was placed midway between the distal and the proximal end of the fingernail (midnail position) corresponding to a size of the hold of approximately 8 $\mathrm{mm}$. First the FDP tendon was loaded alone with $40 \mathrm{~N}$, then the FDS tendon alone with $40 \mathrm{~N}$ and thereafter both tendons, the FDP and the FDS (FDSP) were loaded with each $40 \mathrm{~N}$ weight and the flexion force measured at the fingertip. We choose to apply the same load to the FDS and FDP tendon due to the fact that mass fraction and tension fraction, particularly for the middle finger, are very similar (Brand, 1981). The artificial hold was then moved proximally to the proximal end of the fingernail (endnail position) and the same measurements repeated as above mentioned. Further measurements with the end of the hold at the DIP joint (dip position), midway between the DIP joint and the PIP joint (p2 position) and just distally to the PIP joint (pip position) were performed (Figure 2).

The artificial plane hold was set in a position that the PIP joint was flexed approximately between 20 and $25^{\circ}$ and the DIP joint flexed approximately $50^{\circ}$ (slope grip position). Due to the degree of flexion only the positions midnail, endnail and dip could be performed. Measurements with loaded FDS alone, FDP alone and both tendons together with $40 \mathrm{~N}$ weights each were done as described above.

The data were gathered on a PC and evaluated statistically with the SPSS program (SPSS for Windows Version 16.0, SPSS Inc. Chicago, Illinois, USA). Mean values were compared by the paired students $t$ test and were assumed to be statistically significant when $p<.05$ ( $95 \%$ confidence interval)

\section{Results}

\section{Measurement 1 (Crimp Grip, Figure 4)}

Force generated at the fingertip using the smallest hold (midnail position) with $40 \mathrm{~N}$ load to the FDP tendon was $11.11 \mathrm{~N}(S D$ 0.87) and $8.93 \mathrm{~N}(S D$ 1.92) for the FDS tendon $(p=.002)$, which was a statistically significant difference $(p=.002)$. During crimp grip with the FDP tendon loaded, the fingers remained in a very stable position with the DIP joint in $0-10^{\circ}$ flexion. Except in one ring finger, the DIP joint became flexed about $30-40^{\circ}$ and remained in this position. This finger flexed its DIP joint also in all other crimp grip measurements, except when both, the FDS and FDP tendons were loaded, the DIP joint went in an extended position. With load to the FDS tendon only (midnail position) the DIP joint became extremely hyperextended and was prone to slip off the sensor plate. Force at the endnail position was $12.19 \mathrm{~N}$ $(S D 0.84)$ with load to the FDP and $11.84 \mathrm{~N}$ (SD 1.3) with load to the FDS tendon $(p=.42)$. Hyperextension of the DIP joint with the FDS only loaded was quite less distinct in this position compared with the endnail position. In the dip position the force with load to the FDS tendon was greater (16.91 N,SD 1.64) compared with the force generated with the FDP tendon (12.19 N, $S D$ 1.19) being significant $(p<.001)$. In the more proximal positions $\mathrm{p} 2$ and pip the forces generated by pulling on the FDS tendon increased more compared with the forces generated by the FDP tendon. In the p2 position it was $18.99 \mathrm{~N}(S D$ 1.76) for the FDS and 12.41 N (SD 1.31) for the FDP tendon. In the pip position it was $25.48 \mathrm{~N}$ (SD 2.59) for the FDS and 
Publisher: KINETICS; Journal: JAB:Journal of Applied Biomechanics; Copyright:

$$
\begin{aligned}
& \text { Volume: ; Issue: ; Manuscript: 20100048; Month: ; Year: } \\
& \text { DOI: ; TOC Head: ; Section Head: ; Article Type: Article }
\end{aligned}
$$

$17.14 \mathrm{~N}(S D$ 2.27) for the FDP tendon both being statistically significant. In the most proximal position (pip) the bowstringing of the tendons led to a direct contact of the tendons with the force plate. Therefore these results have to be interpreted carefully.

$\backslash$ insert Figure $4 \backslash$

\section{Measurement 2 (Slope Grip, Figure 4)}

In the slope grip position the FDP tendon generated more force than the FDS tendon with all three measured hold sizes, in midnail position FDP $11.91 \mathrm{~N}$ (SD 1.16), FDS $5.17 \mathrm{~N}$ ( $S D$ 1.99), endnail position FDP $13.49 \mathrm{~N}(S D$ 1.28), FDS $2.28 \mathrm{~N}$ (SD 1.74) and in dip position FDP $15.62 \mathrm{~N}(S D$ 1.16), FDS $10.09 \mathrm{~N}$ ( $S D$ 1.34). All values between FDS and FDP were significantly different. Activating the FDS tendon resulted mostly not in an accurate slope position. The DIP joint rather went into extension so that the flexion force was acting more into a horizontal direction than in a vertical one. These values therefore have to be interpreted carefully.

\section{Measurement 1 and 2 With Load to the FDS and FDP Together (Figure 5)}

When both tendons where loaded together (each with 40 $\mathrm{N})$ the crimp grip position generated always (midnail, endnail and dip position) more flexion force than the slope grip position. For the midnail position the crimp grip generated $20.04 \mathrm{~N}(S D 2.61)$ and the slope grip $17.04 \mathrm{~N}$ (SD 1.95), for the endnail position the crimp grip generated 24.03 N (SD 1.82) and the slope grip 16.31 N (SD 2.03) and for the dip position the crimp grip generated 29.1 N (SD 2.59) and the slope grip 25.71 N (SD 1.92). The differences of the corresponding pairs were all statistically different $(p=.024 ;<0.001 ;=0.001)$.

$\backslash$ Insert Figure $5 \backslash$

\section{$\backslash$ Insert Tables 1 and $2 \backslash$}

According to the lever arms measured on the radiographs, moments (Table 1) which were generated through the PIP joint could be calculated in $\mathrm{Nm}(S D)$ for the crimp grip position and the DIP joint for the slope grip position[AUQ1]. The force required at either the FDS or FDP tendon to generate $100 \mathrm{~N}$ of force at the fingertip for the described measurement positions was calculated also (Table 2).

\section{Discussion}

The crimp grip (Figure 1) is one of the most often used finger position in rock and sport climbing (Bollen, 1988; Marco, 1998). The high amount of load in that typical finger position of a strongly flexed PIP joint and a hyperextended DIP joint does not occur to such an extent in any other sport or professional activities (Schweizer, 2001). It was therefore in rock climbers where closed finger flexor tendon pulley ruptures during high load in the crimp grip position was described initially in 1990 (Bollen, 1990; Tropet, 1990) and was observed in non climbing activities only much later (Schoffl, 2006). But also the slope grip with a flexed DIP and an extended PIP joint used in one- or two finger pockets is associated with injuries not described before (Schweizer, 2003). These injuries arouse the interest in the biomechanics of these special finger positions in climbers particularly the load relationship between the finger flexor tendons and the pulleys (Marco, 1998; Schweizer, 2001; Schweizer, 2003; Vigouroux, 2006, 2008).

Estimating the different tendon forces of the FDS and FDP during slope and crimp grip a static biomechanical model was used by Vigouroux (Vigouroux, 2006) to incorporate FDP intramuscular electromyogram and force measurements at the fingertip. The FDP-to-FDS tendon-force ratio was estimated to be $1.75: 1$ in the crimp grip and $0.88: 1$ in the slope grip position. Our results confirm these observations concerning the crimp grip position where the FDP is more effective than the FDS although only in holds smaller than half the size of the distal phalanx (midnail and endnail position). The climber may automatically, or due to a feedback mechanism, apply more flexion strength to the FDP because this muscle is more effective in this certain finger-position. For larger flat holds however the FDS becomes more efficient than the FDP. We made also the observation that during crimp grip with the FDP tendon loaded, all fingers except one remained in a very stable crimp like position with the distal interphalangeal joint in a slightly $\left(0-10^{\circ}\right)$ flexed position and did not go into hyperextension. It was not necessary to apply an FDS force to keep that equilibrium or to prevent an increased flexion in the DIP joint as supposed by Vigouroux (Vigouroux, 2006) except in one finger. This finger went into flexed position of the PIP as well as the DIP joint simultaneously. Although in an in vivo situation it is likely that an FDS activity has a stabilizing effect to the PIP joint particularly with the cocontraction of the extensor tendons. For the slope grip we could show that the FDP was more than twice as effective then the FDS in holds smaller than half the distal phalanx which is much less than the estimated muscle tension calculated by Vigouroux (Vigouroux, 2006) in holds of about the same size (midnail and endnail position). Only in holds of about the same size of the distal phalanx (dip position) the FDS produces around two thirds of the force of the FDP during the slope grip position. It has to be stated although that the DIP joint goes into extension and applies a more horizontal force to the artificial hold, which is not detected by the force transducer. This demonstrates that the FDS alone is not able to produce adequate force transmission in the distal phalanx in the slope grip position usable in climbing. From this point of view the FDS has no effect on holding strength and it remains unclear, but it is still interesting, why this muscle showed a high muscular activity in this position 
Publisher: KINETICS; Journal: JAB:Journal of Applied Biomechanics; Copyright:

$$
\begin{aligned}
& \text { Volume: ; Issue: ; Manuscript: 20100048; Month: ; Year: } \\
& \text { DOI: ; TOC Head: ; Section Head: ; Article Type: Article }
\end{aligned}
$$

(Vigouroux, 2006). A probable explanation for this high FDS activity might be a stabilizing effect to the PIP joint preventing it to go into the swan neck position (hyperextended PIP joint).

Marco et al. (Marco, 1998) measured forces at the fingertip which where about 2.5 times (index finger), 3 times (middle finger) and 3.5 times (ring finger) less compared with force applied to the flexor tendon (FDP). These values are comparable with those in the current study. The size of the hold they used is about the same we used for the dip position where force at the fingertip was 3.5 times less than the force at the flexor tendons. Those values are also comparable with recently performed dynamic measurements for concentric and eccentric movements through the PIP joint (Schoffl, 2009). In the eccentric situation the difference of the load at the fingertip to the tendon loaded was higher as compared with the concentric movement, which is assumed to be due to friction force between the flexor tendon pulleys and the tendons, which has to be overcome in the eccentric situation additionally (Schweizer, 2009).

Interestingly the finger flexion force created by the FDP tendon did almost not increase or differ in the four smallest holds (endnail to p2) used whereas when the FDS tendon was loaded the flexion force increased continuously from the smallest (endnail) to the greatest hold (pip, Figure 4). This might be due to the two joint linkage or kinetic chain of the PIP and DIP joint. In the endnail and midnail position the FDP tendon exerts a flexion force resulting in a larger moment arm at the PIP joint which does not equalize the smaller moment arm at the DIP joint exactly. Therefore a greater flexion moment is produced through and by the DIP joint as would have been only through the PIP joint. Because we did not localize the moment arms of flexor tendons over the joints we are not able to calculate this two joint linkage exactly.

According to our results the preference for the use of the crimp grip position in rock climbers is not only that the thumb may be used (Figure 1) as an additional holding force and a better fit to holds (Schweizer, 2001) but also the fact that in this position the greatest flexion force and torque can be generated. When both, the FDS and FDP tendons are loaded, the crimp grip always generates more flexion moment than the slope grip independently on the size of the hold. Although this grip position might be more prone to pulley injuries and overload to the finger joints, it seems to be the most efficient particularly for small holds.

Limitations of the study are that probable muscular influences like pretension or the generated strength according to different positions of contraction of the FDS and FDP muscles are not taken into consideration. Concerning the calculations of the different moments the distances from the PIP joint to the edge of the hold was used which is a simplification for the situation of the crimp grip activated by the FDP tendon. We also did not incorporate the effect of the extensor tendons, the lumbricals and the interossei in our measurements. A small effect cannot be excluded although these muscles generate no flexion force in the DIP or PIP joints. The intercalated joint (DIP) may alter the kinetic chain which is shown in the nonlinear increase of the finger tip flexion strength with the FDP/crimp grip hold series (discussed above). Also the effect of internal friction force between tendons and pulleys as well as between the other tissues (joints, subcutaneous tissue, skin) was not taken into consideration although the testing situation was always the same and near static. A further performance-limiting factor in rock climbing is the friction between skin and the surface of the hold. Many variables like the amount of sweating, humidity, as well as temperature of the air and rock may be even more important than the positions of joints of the finger.

\section{References}

Bollen, S.R. (1988). Soft tissue injury in extreme rock climbers. British Journal of Sports Medicine, 22, 145-147.

Bollen, S.R. (1990). Injury to the A2 pulley in rock climbers. Journal of Hand Surgery (Edinburgh, Lothian), 15, 268-270.

Brand, P.W., Beach, R.B., \& Thompson, D.E. (1981). Relative tension and potential excursion of muscles in the forearm and hand. The Journal of Hand Surgery, 6, 209-219.

Marco, R.A., Sharkey, N.A., Smith, T.S., \& Zissimos, A.G. (1998). Pathomechanics of closed rupture of the flexor tendon pulleys in rock climbers. Journal of Bone and Joint Surgery Am, 80, 1012-1019.

Moor, B.K., Nagy, L., Snedeker, J.G., \& Schweizer, A. (2009). Friction between finger flexor tendons and the pulley system in the crimp grip position. Clinical Biomechanics (Bristol, Avon), 24, 20-25.

Schoffl, I., Oppelt, K., Jungert, J., Schweizer, A., Bayer, T., Neuhuber, W., et al. (2009). The influence of concentric and eccentric loading on the finger pulley system. Journal of Biomechanics, 42, 2124-2128.

Schoffl, V.R., \& Jungert, J. (2006). Closed flexor pulley injuries in nonclimbing activities. The Journal of Hand Surgery, 31, 806-810.

Schweizer, A. (2001). Biomechanical properties of the crimp grip position in rock climbers. Journal of Biomechanics, 34, 217-223.

Schweizer, A. (2003). Lumbrical tears in rock climbers. Journal of Hand Surgery (Edinburgh, Lothian), 28, 187-189.

Schweizer, A., Frank, O., Ochsner, P.E., \& Jacob, H.A. (2003). Friction between human finger flexor tendons and pulleys at high loads. Journal of Biomechanics, $36,63-71$.

Schweizer, A., Moor, B.K., Nagy, L., \& Snedecker, J.G. (2009). Static and dynamic human flexor tendonpulley interaction. Journal of Biomechanics, 42, 1856-1861.

Tropet, Y., Menez, D., Balmat, P., Pem, R., \& Vichard, P. (1990). Closed traumatic rupture of the ring finger flexor tendon pulley. The Journal of Hand Surgery, $15,745-747$. 
Publisher: KINETICS; Journal: JAB:Journal of Applied Biomechanics; Copyright:

Volume: ; Issue: ; Manuscript: 20100048; Month: ; Year:

\section{DOI: ; TOC Head: ; Section Head: ; Article Type: Article}

Verdan, C. (1960). Syndrome of the quadriga. The Surgical Clinics of North America, 40, 425-426.

Vigouroux, L., \& Quaine, F. (2006). Fingertip force and electromyography of finger flexor muscles during a prolonged intermittent exercise in elite climbers and sedentary individuals. Journal of Sports Sciences, 24, 181-186.

Vigouroux, L., Quaine, F., Labarre-Vila, A., \& Moutet, F. (2006). Estimation of finger muscle tendon tensions and pulley forces during specific sport-climbing grip techniques. Journal of Biomechanics, 39, 2583-2592.

Vigouroux, L., Quaine, F., Paclet, F., Colloud, F., \& Moutet, F. (2008). Middle and ring fingers are more exposed to pulley rupture than index and little during sport-climbing: a biomechanical explanation. Clinical Biomechanics (Bristol, Avon), 23, 562-570. 
Publisher: KINETICS; Journal: JAB:Journal of Applied Biomechanics; Copyright:

Volume: ; Issue: ; Manuscript: 20100048; Month: ; Year:

DOI: ; TOC Head: ; Section Head: ; Article Type: Article

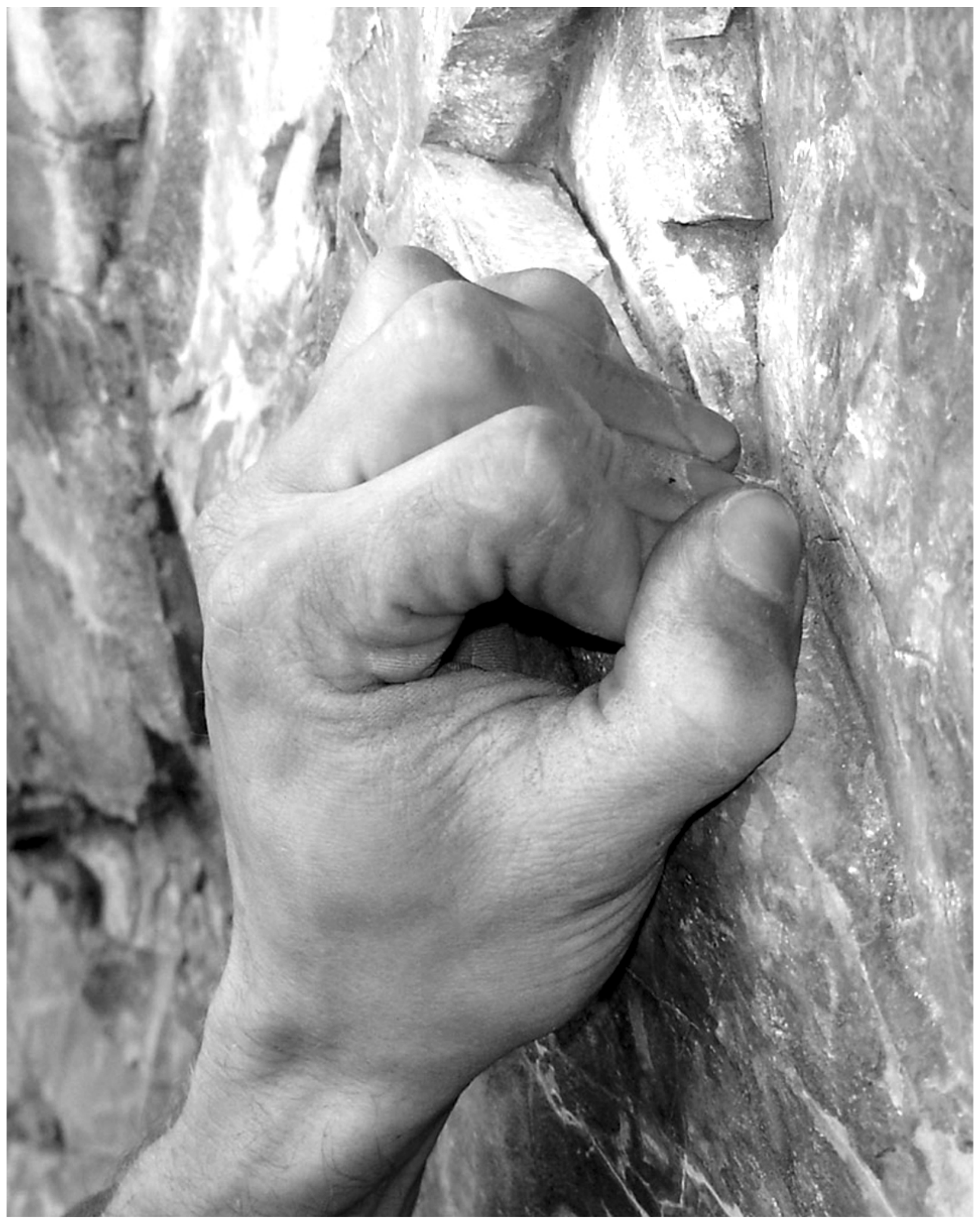

Figure 1 - Hold grasped with the crimp grip position, the PIP joints are flexed and the DIP joints hyperextended. The proximity of the hold allows the thumb to participate also for small holds. 
Publisher: KINETICS; Journal: JAB:Journal of Applied Biomechanics; Copyright:

Volume: ; Issue: ; Manuscript: 20100048; Month: ; Year:

DOI: ; TOC Head: ; Section Head: ; Article Type: Article

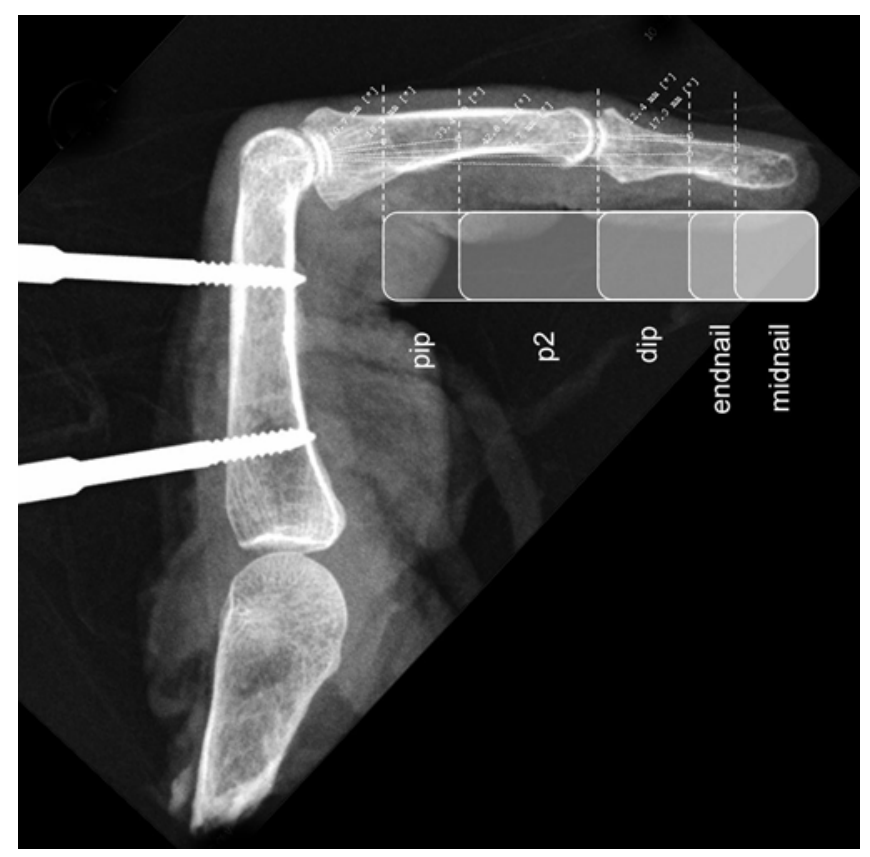

Figure 2 - Radiograph (lateral view) of a cadaver finger with the different sizes of the holds being used. Measurements on x-ray of the distances from the edge of the hold to center of rotation of the DIP and PIP joint are shown. 
Publisher: KINETICS; Journal: JAB:Journal of Applied Biomechanics; Copyright:

Volume: ; Issue: ; Manuscript: 20100048; Month: ; Year:

DOI: ; TOC Head: ; Section Head: ; Article Type: Article

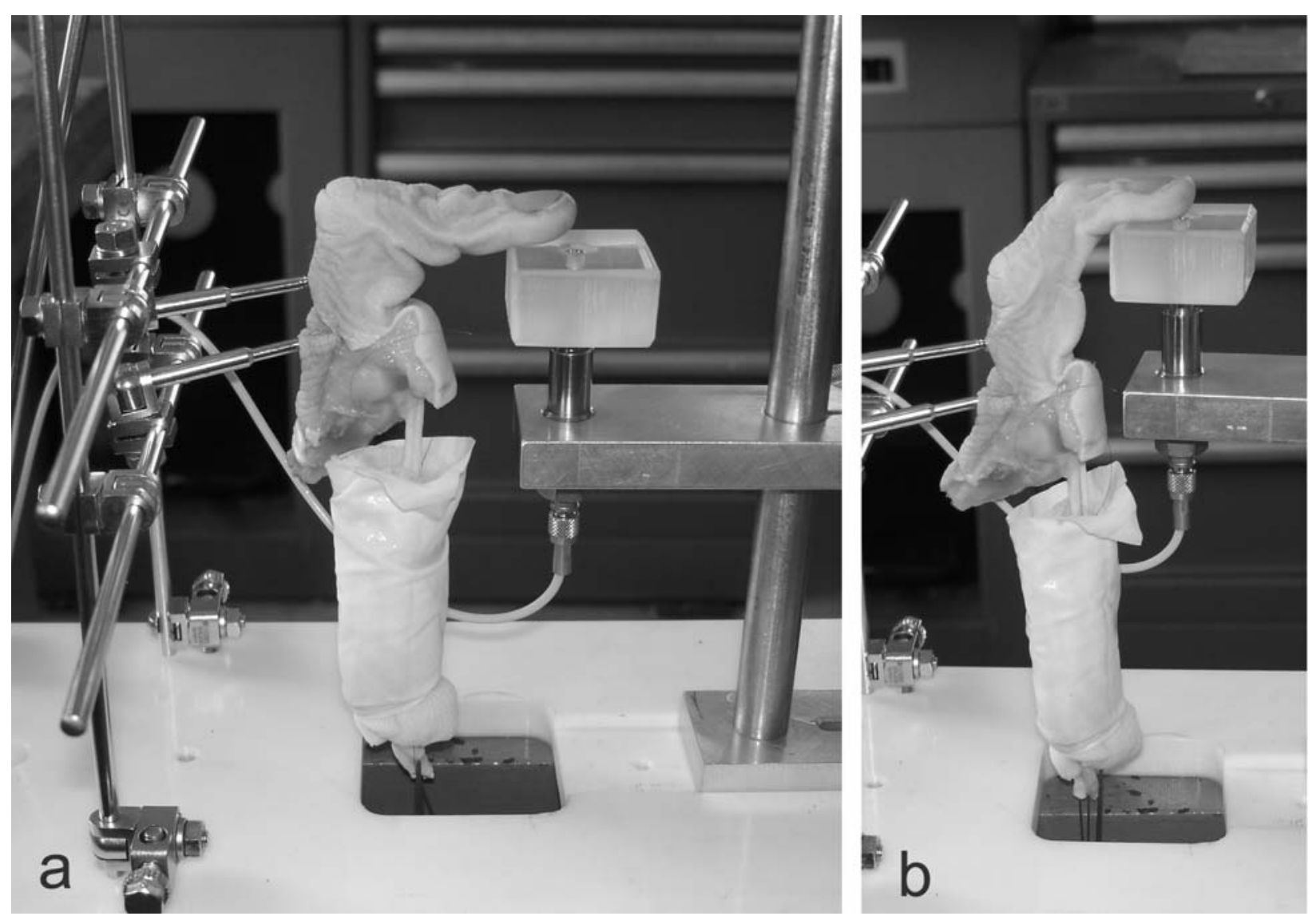

Figure 3 - Crimp grip (a) and slope grip (b) positions with hold size "endnail" in the testing set up. 
Publisher: KINETICS; Journal: JAB:Journal of Applied Biomechanics; Copyright:

Volume: ; Issue: ; Manuscript: 20100048; Month: ; Year:

DOI: ; TOC Head: ; Section Head: ; Article Type: Article

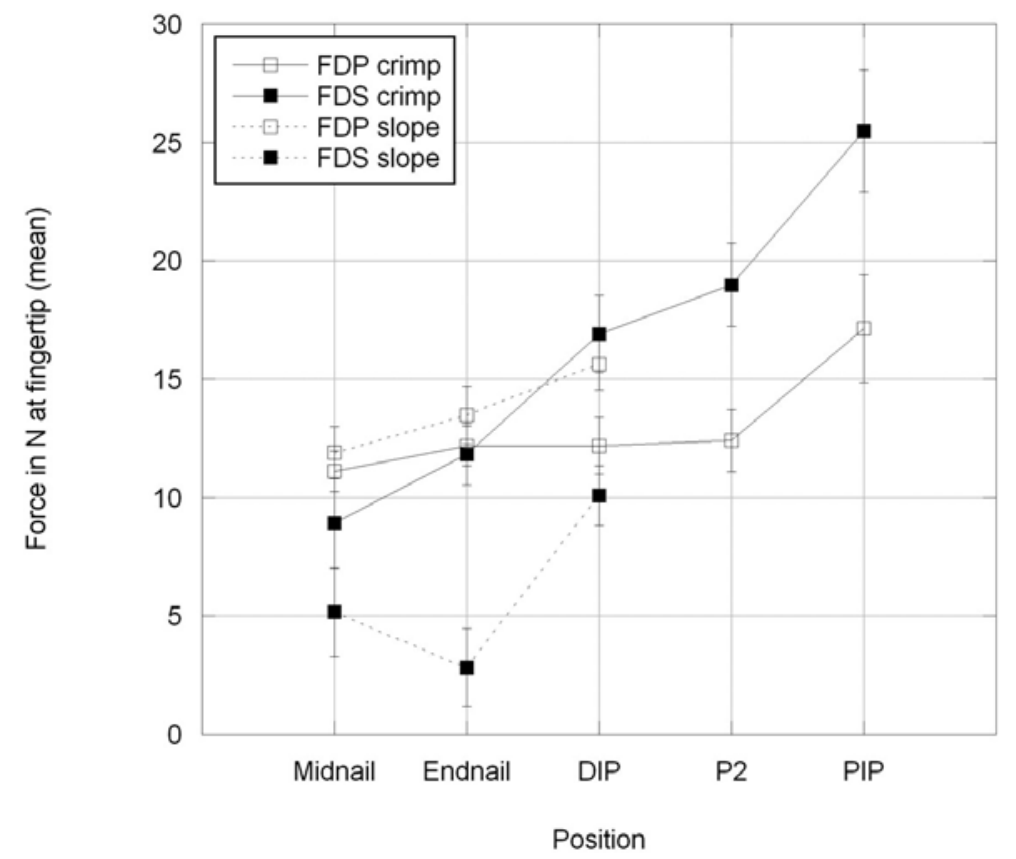

Figure 4 - Forces $(\mathrm{N})$ measured at the fingertip (mean: square; $S D$ ) for the different positions / hold sizes and single loaded FDP or FDS tendons. 
Publisher: KINETICS; Journal: JAB:Journal of Applied Biomechanics; Copyright:

Volume: ; Issue: ; Manuscript: 20100048; Month: ; Year:

DOI: ; TOC Head: ; Section Head: ; Article Type: Article

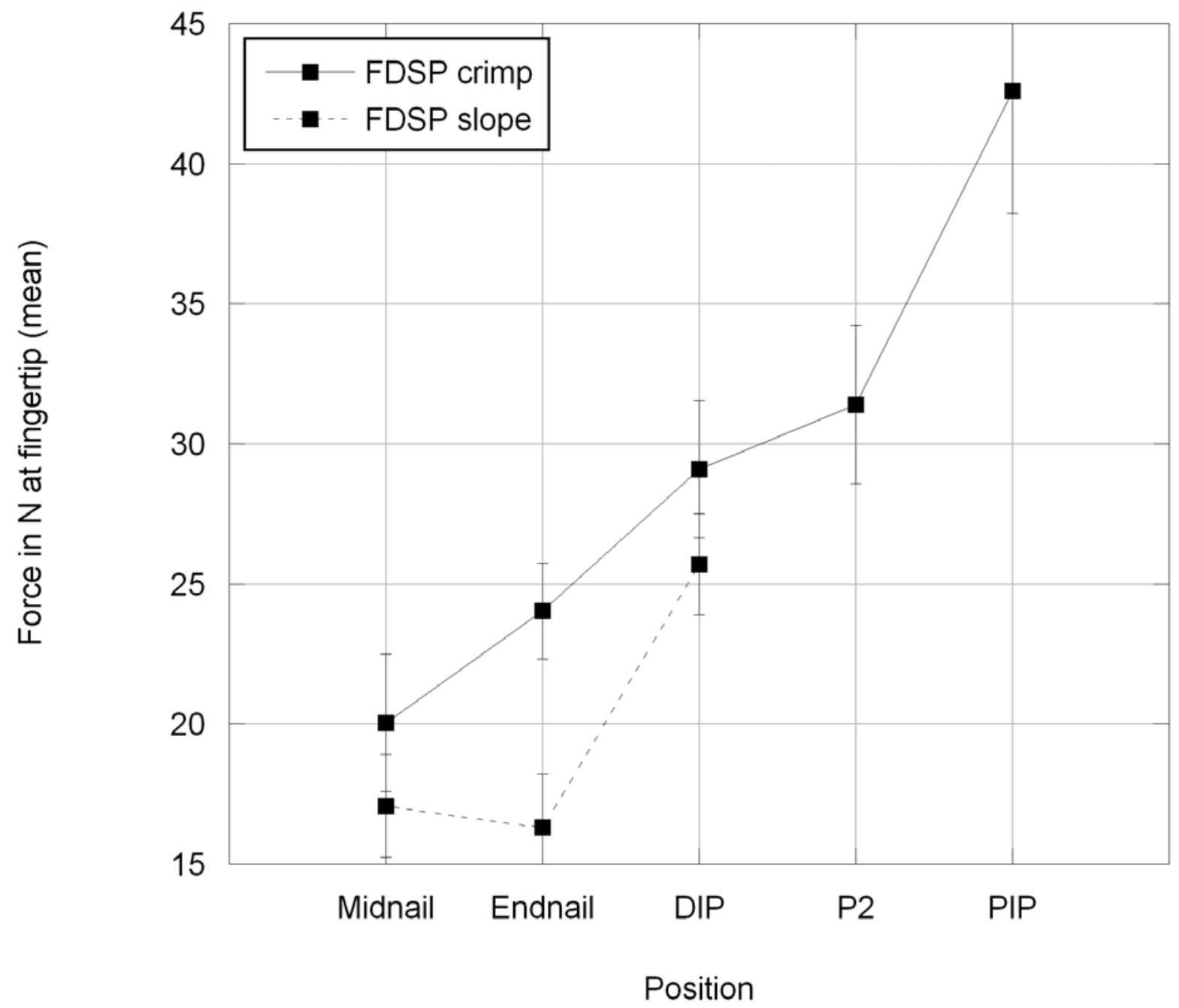

Figure 5 - Forces $(\mathrm{N})$ measured at the fingertip (mean: square; $S D$ ) for the different positions / hold sizes and simultaneously loaded FDS and FDP tendons. 
Publisher: KINETICS; Journal: JAB:Journal of Applied Biomechanics; Copyright:

Volume: ; Issue: ; Manuscript: 20100048; Month: ; Year:

DOI: ; TOC Head: ; Section Head: ; Article Type: Article

Table 1

\begin{tabular}{|c|c|c|c|c|c|c|c|c|}
\hline & \multicolumn{2}{|c|}{ Midnail } & \multicolumn{2}{|c|}{ Endnail } & \multicolumn{2}{|c|}{ dip } & \multicolumn{2}{|c|}{$\mathrm{p} 2$} \\
\hline & FDP & FDS & FDP & FDS & FDP & FDS & FDP & FDS \\
\hline Nm PIP & 0.49 & 0.39 & 0.48 & 0.47 & 0.37 & 0.51 & 0.21 & 0.32 \\
\hline$S D$ & 0.07 & 0.10 & 0.04 & 0.07 & 0.03 & 0.05 & 0.02 & 0.04 \\
\hline Nm DIP & 0.21 & & 0.17 & & & & & \\
\hline$S D$ & 0.02 & & 0.02 & & & & & \\
\hline
\end{tabular}

Table 2

\begin{tabular}{|c|c|c|c|c|c|c|c|c|}
\hline & \multicolumn{2}{|c|}{ Midnail } & \multicolumn{2}{|c|}{ Endnail } & \multicolumn{2}{|c|}{ dip } & \multicolumn{2}{|c|}{ p2 } \\
\hline & FDP & FDS & FDP & FDS & FDP & FDS & FDP & FDS \\
\hline For $100 \mathrm{~N}$ & 361.9 & 470.7 & 329.5 & 341.2 & 330.8 & 238.5 & 325.3 & 212.2 \\
\hline$S D$ & 27.4 & 123.0 & 22.3 & 35.8 & 30.6 & 22.5 & 32.5 & 19.2 \\
\hline
\end{tabular}


Publisher: KINETICS; Journal: JAB:Journal of Applied Biomechanics; Copyright:

Volume: ; Issue: ; Manuscript: 20100048; Month: ; Year:

DOI: ; TOC Head: ; Section Head: ; Article Type: Article

\section{Author Queries}

[AUQ1] Please supply a short table title for your two tables. 